\title{
Marcus-Gunn Jaw Winking Syndrome and Gustatory Sweating in Long Standing Poorly Controlled Diabetes: A Case Report
}

\author{
Deep Dutta*, Indira Maisnam, Sujoy Ghosh, Pradip Mukhopadhyay, Satinath Mukhopadhyay, \\ Subhankar Chowdhury \\ Department of Endocrinology \& Metabolism, IPGMER \& SSKM Hospital, Kolkata, India. \\ Email: *deepdutta2000@yahoo.com
}

Received October $9^{\text {th }}, 2011$; revised November $18^{\text {th }}, 2011$; accepted December $16^{\text {th }}, 2011$

\begin{abstract}
Introduction: Marcus Gunn jaw winking syndrome (MGJWS) is a rare congenital disorder belonging to the synkinetic eye movement group of disorders observed in children. It occurrence in adults and patients with diabetes has not been reported. Material and Methods: A 64-year man with poorly controlled diabetes of 18 years presented with 3-month history of jaw winking on the left side along with gustatory sweating, which was managed conservatively. There was spontaneous improvement in jaw wink at 4 months of follow up. Conclusions: Acquired causes of MGJWS are not known. This is probably the first report of this syndrome occurring at such a late age. Long standing poorly controlled diabetes may have had some role in the development of jaw winking in this patient.
\end{abstract}

Keywords: Marcus Gunn Syndrome; Jaw Winking; Gustatory Sweating; Diabetes

\section{Introduction}

Marcus Gunn Jaw Winking Syndrome (MGJWS) is a congenital unilateral non progressive neurogenic ptosis, usually evident at birth characterized by simultaneous winking during chewing of food, first reported by Marcus Gunn in 1883 [1]. It is usually sporadic but can rarely be familial. It constitutes about $4 \%-6 \%$ of congenital ptosis [2]. The natural history of MGJWS is not well known with some reports suggesting that the disease becomes less apparent with age. The pathogenesis of disease is also controversial with the most accepted theory being aberrant innervation of division of occulomotor nerve by a branch of motor division of trigeminal nerve [3]. Its development in later life is not known and its occurrence in diabetes has never been reported.

\section{Case Report}

Sixty-four year gentleman presented with involuntary winking of left eye during chewing noticed for the last three months (Figure 1) with increased sweating mainly over the fore head during meals, for the same duration. (Figure 2) The sweating was worse on eating spicy food. He had no evidence of any other cranial nerve involvement. He complained of tingling and numbness of bilat-

${ }^{*}$ Corresponding author. eral sole of foot for last 2 years. He was diagnosed with diabetes since 46 years of age, initially on sulfonylureas and metformin, but now on insulin for the last 8 years due to persistently uncontrolled blood sugars. His current HbA1c was 9.6\%. Monofilament testing (Semmes-Weinstein $10 \mathrm{~g}$ monofilament) was normal, but the mean vibration perception threshold (Vibrometer-VPT, Diabetic Foot Care, Chennai, India) on testing of bilateral soles was 24 hertz suggestive of severe neuropathy. Patient complained of impotence for last 10 years along with postural symptoms. He had postural hypotension, and electrocardiography (ECG) showed lack of heart rate variability during Valsalva. He was non hypertensive and had no evidence of any other microvascular or macrovascular complications.

He was managed conservatively and last evaluated, 7 months since the initial development of symptoms; there was significant improvement in the jaw winking. He also had a better glycemic control with HbA1c of 7.8\%.

\section{Discussion}

MGJWS, characterized by involuntary winking of eyes during chewing, is believed to be due to an aberrant connection between the mandibular division of trigeminal nerve (innervating the external pterygoid muscle) and one of the divisions of occulomotor nerve (innervating 


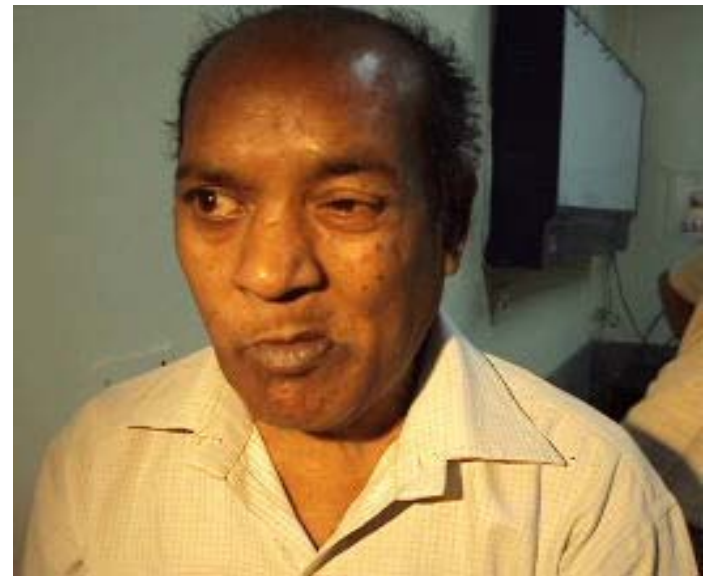

(a)

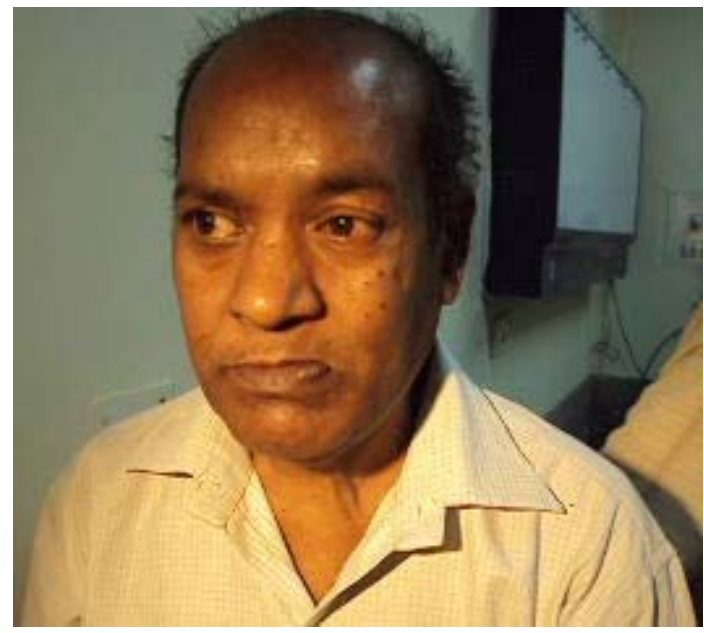

(b)

Figure 1. (a) Winking during chewing of food; (b) Absence of wink after finishing chewing of food.

the levator palpebralis superioris of the upper eye lid) [3]. This hypothesis is supported by the synkinesis that has been observed during electromyographic studies [3]. Hence it is also known as Trigemino-oculomotor synkinesis. Also it has been hypothesized that release of phylogenetically older neural mechanisms due to a lesion in the brain stem may be responsible for the occurrence of this trigemino-ocular synkinesis, as seen with other synkinetic movements like palmomental reflex and primitive grasp feeding reflexes. Evidence favoring this is the cofiring of the occulomotor innervated extra-ocular muscles along with muscles of mastication (innervated by trigeminal nerve) on EMG in normal individuals [4].

The disease is mostly congenital, evident at birth, usually non progressive and frequently associated with blepharoptosis, strabismus, amblyopia and other extra ocular muscle palsy, most common being superior rectus palsy [5].

In our patient, the age of onset of jaw winking was 64

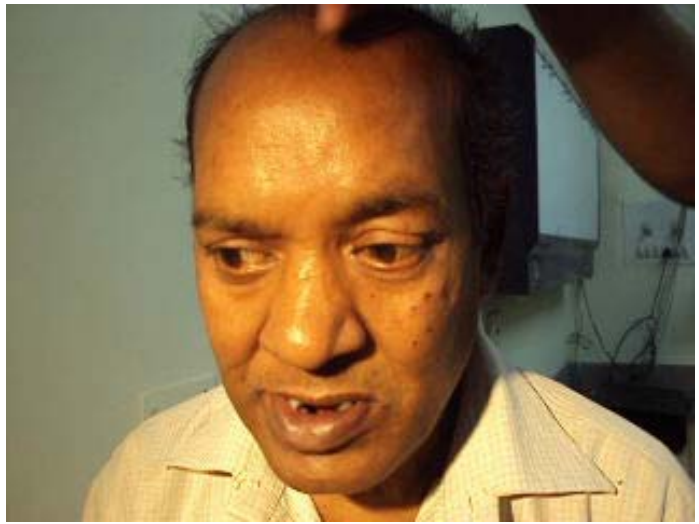

Figure 2. Glistening of forehead due to appearance of sweat pellets following a small snack (Gustatory sweating).

years, suggesting that MGJWS in his case is an acquired phenomenon and not congenital. There was no associated strabismus or palsy of any other extra ocular muscle. In the background of long standing poorly controlled diabetes and associated autonomic and distal symmetrical peripheral neuropathy, it may be said that diabetes may have had some role in the development of this syndrome in our patient.

Sub-clinical involvement of cranial nerves is common in diabetes. Third cranial nerve is the most commonly involved followed by sixth and seventh cranial nerves [6]. Also involvement of trigeminal nerve is not uncommon in diabetes, with mandibular division especially prone to injury [7]. In a recent study as many as $11 \%$ of third nerve palsies were believed to be due to diabetes [8]. Palsies of third cranial nerves in diabetes are usually abrupt in onset with gradual recovery over 3 - 5 months [9].

It may be postulated that injury to trigeminal and occulomotor nerves due to poorly controlled diabetes of long duration and subsequent some degree of recovery may have lead to an aberrant connection between the mandibular division of trigeminal nerve and occulomotor nerve thus explaining this late onset MGJWS.

Interesting was also the simultaneous occurrence of gustatory sweating while eating in our patient. Gustatory sweating is a strong marker of autonomic dysfunction. Our patient also had other features of dysautonomia like impotence, postural symptoms, postural hypotension and lack of heart rate variations in ECG on Valsalva. He also had distal symmetrical peripheral neuropathy.

Treatment of MGJWS is surgical correction, usually reserved for severe cases. Surgical correction involves correction of ptosis along with correction of wink response, as isolated ptosis correction may lead to worsening of wink. Levator function obliteration has been used to dampen the wink response [10]. Severe gustatory sweating is usually treated with oral anti-cholinergics. Topical glycopyrrolate has also been found to be beneficial [11]. 
Our patient's jaw winking was not severe to hamper his life. We followed up the patient, hoping that a better glycemic control may lead to some improvement as most of the diabetic craniopathies resolve spontaneously over months. Gustatory sweating was also not severe to warrant anti cholinergic therapy and was managed by asking the patient to avoid spicy and very hot food. There was spontaneous improvement in the jaw wink at 4 months of follow up i.e. seven months from the initial development. The patient also achieved a better glycemic control with last HbA1c being 7.8\%. This improved glycemic control may have had some role in this spontaneous resolution of synkinesis.

This is perhaps the first report of occurrence of Marcus Gunn jaw winking syndrome in a patient of diabetes who also had gustatory sweating, and which improved spontaneously with better glycemic control.

\section{REFERENCES}

[1] R. M. Gunn, "Congenital Ptosis with Peculiar Associated Movements of the Affected Lid," Transactions of the Ophthalmological Society of the United Kingdom, Vol. 3, 1883, pp. 283-287.

[2] S. P. Pratt, C. K. Beyer and C. C. Johnson, "The Marcus Gunn Phenomenon. A Review of 71 Cases,” Ophthalmology, Vol. 91, No. 1, 1984, pp. 27-30.

[3] S. Duke Elder, "Normal and Abnormal Development; Congenital Deformities,” In: System of Ophthalmology, Vol. 3, CV Mosby, St. Louis, 1963, pp. 900-905.
[4] K. Sano, “Trigemino-Oculomotor Synkinesis,” Neuralgia, Vol. 1, 1959, pp. 29-51.

[5] S. G. Pratt, C. K. Beyer and C. C. Johnson, "The Marcus Gunn Phenomenon: A Review of 71 Cases,” Ophthalmology, Vol. 91, No. 1, 1984, pp. 27-30.

[6] A. K. Asbury, "Focal and Multifocal Neuropathies of Diabetes,” In: P. J. Dyck, P. K. Thomas, A. K. Asbury, A. I. Winegrad and D. Porte, Eds., Diabetic Neuropathy, Saunders, Philadelphiam,1987, pp. 45-55.

[7] G. Cruccu, R. Agostino, M. Inghilleri, P. Innocenti, A. Romaniello and M. Manfredi, "Mandibular Nerve Involvement in Diabetic Polyneuropathy and Chronic Inflammatory Demyelinating Polyneuropathy,” Muscle \& Nerve, Vol. 21, No. 12, 1998, pp. 1673-1679. doi:10.1002/(SICI)1097-4598(199812)21:12<1673::AIDMUS8>3.0.CO;2-A

[8] J. R. Keane, "Third Nerve Palsy: Analysis of 1400 Personally-Examined Inpatients,” Canadian Journal of Neurological Sciences, Vol. 37, No. 5, 2010, pp. 662-670

[9] D. Ziegler, “Diabetic Peripheral Neuropathy,” In: R. I. G. Holt, C. S. Cockram, A. Flyvbjerg and B. J. Goldstein, Eds., Text Book of Diabetes, 4th Edition, Wiley-Blackwell, Hoboken, 2010, p. 618.

[10] D. B. Dillman and R. L. Anderson, "Levator Myectomy in Synkinetic Ptosis," Archives of Ophthalmolgoy, Vol. 102, No. 3, 1984, pp. 422-423. doi:10.1001/archopht.1984.01040030340033

[11] J. D. Urman and A. M. Bobrove, "Diabetic Gustatory Sweating Successfully Treated with Topical Glycopyrrolate: Report of a Case and Review of the Literature," Archives of Internal Medicine, Vol. 159, No. 8, 1999, pp. 877-878. doi:10.1001/archinte.159.8.877

\section{Abbreviations}

MGJWS: Marcus Gunn Jaw Winking Syndrome. 